\title{
ASSESSMENT OF ANTHROPOMETRIC MEASUREMENT OF UNDER 5 AGES OF CHILDREN IN TRIBAL AREA AND ITS CORRELATION WITH SOCIO- DEMOGRAPHIC FACTORS
}

\author{
${ }^{\mathrm{ac}} \mathrm{GMC}$, Gondia, Maharashtra, India \\ ${ }^{\mathrm{b}}$ Zydus Medical College, Gujarat, India
}

MAHESH PURI ${ }^{a 1}$, GANESH TATHE $^{\mathrm{b}}$ AND ANSHADA BATHE

\begin{abstract}
Malnutrition is one of the leading causes of morbidity and mortality among children under the age of 5 years in low and middle income countries like India. Children with severe acute malnutrition (SAM) are more likely to die than children without malnutrition. The anthropometric measurements of under 5 children have not been clearly assessed in Indian scenario. The objectives of study were to assess the anthropometric measurement, proportion of malnutrition among children aged 0-60 months and its correlation with socio-demographic factors with special reference to tribal population, in the Gondia district in Maharashtra. This study was a hospital-based observational study, conducted in GMC, Gondia. The WHO growth standards were used to calculate conventional indices of malnutrition (underweight, stunting and wasting) and composite index of anthropometric failure (CIAF). Univariate, bivariate and multiple logistic regression analysis was also used to find out the correlates of malnutrition. The participants were universal sample of 72 children ( 9 tribal and 63 non-tribals) was included in this study selected from immunization OPD of tertiary care centre over the period of 2 months. Overall, the proportion of malnourished children (MAM) under the age of 5 years was $\mathbf{7 3 . 6 \%}$ and SAM was $52.8 \%$. The current study states that the proportion of underweight, stunting and wasting was $54.17 \%, 36.11 \%$ and $45.8 \%$ respectively. The factors as occupation of father, birth weight and weight gain during pregnancy were significantly associated with malnourished children. On multivariate regression, only birth weight was confirmed as statistically significant factor $(\mathrm{P}=0.001)$. When tribal and nontribal children are compared, factors as age of mother at first delivery, education, income and Socio-economic status were found to be statistically significantly related to tribal population. Hence, it can be said that major cause for malnutrition in children was lower income group and early age of mother at first delivery due to cultural practices. A multi-sector approach is essential to address malnutrition in this part. There is a need for further studies not only focusing on anthropometry but also large scale multicentric studies for proper availability of data.
\end{abstract}

KEYWORDS: Malnutrition, Undernutrition, Tribal, Gondia, CIAF

Globally, child malnutrition is a public health problem with major consequences for child survival, damaging the cognitive and physical development of children and the economic productivity of individuals and societies (Black et al., 2013). Malnutrition is the key risk factor for morbidity and mortality among this age group. One in five children in the developing world is undernourished, and under-nutrition is associated with $50 \%$ of child deaths worldwide (Grieken et al., 2013). Malnutrition contributes to $50 \%$ of all child deaths and $11 \%$ of the total global disability-adjusted-life-years worldwide. Geographically, $70-80 \%$ of undernourished children worldwide live in lower and middle income countries (Park et al., 2013).

Under 5 children constitute the most vulnerable segment of any country as growth during childhood is widely used as marker to assess adequate health, nutrition, development of the child (Manjunath et al., 2014).

Undernutrition accounts for $45 \%$ of deaths of children younger than 5 years, and contributes to more than three million deaths every year (Black et al., 2013) (Wang et al., 2016) (Black et al., 2013). Acute malnutrition is an indicator of an emergency that requires urgent action. The UN estimates that acute malnutrition affects $8 \%$ of children (52 million) across the world (1 in 12 children in this age group) (Black et al., 2013) (UNICEF, 2014). Globally, acute malnutrition accounts for $>50 \%$ of cases of childhood mortality (about 3.5 million deaths) in children under 5 each year (UNICEF, 2009). The global estimates in children less than five years of age show that stunting, after continuous decline between 2000 and 2012, still affects $25 \%$ of children, and 92\% of stunted children are in Asia and Africa (Arif, 2017). Severe acute malnutrition (SAM) is a major cause of child mortality under 5 years of age. Severe acute malnourished children are nine times more likely to die than healthy children (UNICEF, 2009). Globally, it is estimated that there are nearly 20 million severe acute malnourished children. The UN estimates that around one million children under the age of 5 die every year from SAM (WHO and UNICEF, 2007).

${ }^{1}$ Corresponding author 
Malnutrition affect over the $30 \%$ children of under 5 age group in India (Manjunath et al., 2014). Out of total population, scheduled tribes (STs) comprise 8.2\% of India's population. In comparison with the wider community in India, this community has historically been subject to major social disadvantage. There are 104 million people from 705 distinct scheduled tribes. Within this population, 11.5 million are under the age of five years. More than half (54\%), or 6.2 million of these tribal children are stunted in India (Tubid, 2015).

Moreover, several studies have shown that degree of under-nutrition is higher among the underprivileged communities and Tribal being the more vulnerable ones (Debnath and Bhattacharjee, 2014). However, few studies have been conducted to assess the determinants of SAM, particularly in this study area. Therefore, the objective of this study was to determine the socio-demographic and economic factors, and child care practice-associated determinants, that may help to strengthen the management of SAM among children aged 6-59 months in the Gondia district of Maharashtra.

\section{METHODS}

\section{Study Area}

This study was conducted at Immunization OPD, Govt. Medical College, Gondia through Department of Community Medicine. This is tribal district and it is most eastern district of Maharashtra. It is located at central India and is $125 \mathrm{~km}$ from Nagpur, which is sub-capital of Maharashtra.

\section{Study Design and Selection of Participants}

A hospital based observational study was conducted from May to September 2019. The sample size was universal sampling. The sample was formed of children of age group up to 60 months attending Immunization OPD in period of 2 month. Total participants who were included in study came out to be 72.

The screening of all children aged up to 60 months were evaluated for anthropometric measurements (weight and height) and compared with WHO 2006 simplified growth standards to categorize the children as a malnourished child (weight for height $<-2 \mathrm{SD}$ ). Study participants with chronic diseases and unwilling parents/guardian of children were excluded from study.

\section{Data Collection and Statistical Analysis}

The data were collected through face-to-face interviews using a pre-tested structured questionnaire after taking proper consent. Anthropometric measurements (weight and recumbent length/height) of the children were taken. For this, undressed or minimally dressed children were weighed using a Salter scale weighing machine was used and recumbent length/height was measured by using a height board/infantometer as per age. Addition of $0.7 \mathrm{~cm}$ is done when standing height was converted to recumbent length. Validation of instruments and measurements was done on a daily basis. Collected data were entered into MS Excel 2016. The entered data were then exported to epi-info 1.4.3. The association between malnourished participants and exposure variables was analyzed by using bivariate and multivariate regression analysis. A value of $p<0.05$ was considered to be significant where the confidence interval for OR was set at $95 \%(95 \% \mathrm{CI})$.

The height-for-age indicates linear growth retardation and cumulative growth deficits. It captures chronic malnutrition and reflects failure to receive adequate nutrition over a long period and is also affected by recurrent and chronic illness. Weight-for-age is a composite index of growth as it accounts both acute and chronic malnutrition. Weight-for-height is mainly acute index of malnutrition, also called as undernutrition. CIAF (Composite index of anthropometric failure) was considered as positive if one or more of already mentioned parameters were positive.

\section{Variables}

SAM (Severe acute malnutrition) and MAM (Moderate acute malnutrition) refers to the condition that is identified through measurement of weight for height (Undernutrition) $<-3 \mathrm{SD}$ and $<-2 \mathrm{SD} \mathrm{Z}$-score below the median among children aged up to 60 months according to WHO 2006 growth standards repesctively (WHO and UNICEF, 2009). Socio-economic status for the household was assessed by the modified Kuppuswamy scale, where households were divided into five socioeconomic layers from lowest to highest. Other factors were conveniently grouped or grouped according to standard guidelines.

\section{Questionnaire}

A semi-structured pre-tested questionnaire was developed based on the study objectives including educational status of parents, mother's age, and breastfeeding details along with basic demographic, personal and cultural details. 


\section{Ethical Considerations}

Ethical approval was provided by the Institutional Review Board, GMC, Gondia [Reg no. ECR/1033/Inst/MH2018]. Informed written consent was obtained from parents of participant. Confidentiality of the information provided by respondents was maintained. Those children identified as having SAM or moderate acute malnutrition but were not receiving appropriate care and treatment were referred to the nutrition rehabilitation home, GMC, Gondia. Moreover, nutritional counseling was provided during data collection.

\section{RESULTS}

This hospital based study was carried out among 72 children aged up to 60 months in GMC, Gondia. CIAF showed that 53 participants out of 72 were malnourished.
The proportion of MAM children were $73.6 \%$ and SAM children were $52.8 \%$. The current study states that the proportion of underweight, stunting and wasting was $54.17 \%, 36.11 \%$ and $45.8 \%$ respectively. The mean \pm sd for ages of the participants was $23.51 \pm 16.01$ months and height of them was $82.4 \pm 15.7 \mathrm{~cm}$. Age group of 3 to 5 year was consisted of maximum participants i.e. 39 $(54.2 \%)$. The group was male dominated with $56.9 \%$ boys. Total $8(11.1 \%)$ mothers were having their age less than 20 years or more than 35 years. Out of total, 32 (44.4\%) mothers undergone caesarean delivery and 20 (27.8\%) mothers gave birth to underweight children. Exclusive Breastfeeding was given by 44 (61.1\%) mothers. Lower percentage of formula fed and bottle fed children were observed. Table 1 shows the general characteristics of the participants in the study.

Table 1: Baseline characteristic of participants $(n=72)$

\begin{tabular}{|c|c|c|c|}
\hline Characteristics & Groups & Number of Participants & Percentage \\
\hline \multirow{3}{*}{$\begin{array}{c}\text { Age of participants } \\
\text { (Month) }\end{array}$} & 0 to 6 & 16 & 22.2 \\
\hline & 7 to 24 & 17 & 23.6 \\
\hline & 25 to 60 & 39 & 54.2 \\
\hline \multirow{2}{*}{ Sex } & Male & 41 & 56.9 \\
\hline & Female & 31 & 43.1 \\
\hline \multirow{2}{*}{$\begin{array}{c}\text { Mother's age at first } \\
\text { delivery (Years) }\end{array}$} & 20 to 34 & 64 & 88.9 \\
\hline & $<20$ or $>34$ & 08 & 11.1 \\
\hline \multirow{2}{*}{ Adequate ANC Visit } & Present & 62 & 86.1 \\
\hline & Absent & 10 & 13.9 \\
\hline \multirow{2}{*}{ h/o Malnutrition } & Present & 4 & 5.6 \\
\hline & Absent & 68 & 94.4 \\
\hline \multirow{2}{*}{ Type of Delivery } & Normal & 40 & 55.6 \\
\hline & Caesarean & 32 & 44.4 \\
\hline \multirow{2}{*}{ Birth Weight (gm) } & 1500 to 2499 & 20 & 27.8 \\
\hline & 2500 to 3999 & 52 & 72.2 \\
\hline \multirow{2}{*}{$\mathrm{BF}$ given } & Expected time & 38 & 52.8 \\
\hline & After expected time & 34 & 47.2 \\
\hline \multirow{2}{*}{ Exclusive BF } & Given & 44 & 61.1 \\
\hline & Not Given & 28 & 38.9 \\
\hline \multirow{2}{*}{ Father's educational level } & Illiterate & 09 & 12.5 \\
\hline & Literate & 63 & 87.5 \\
\hline \multirow{3}{*}{$\begin{array}{l}\text { Socioeconomic status } \\
\text { (Mod. Kuppuswamy) }\end{array}$} & Lower & 30 & 41.7 \\
\hline & Middle & 26 & 36.1 \\
\hline & Higher & 16 & 22.2 \\
\hline \multirow{2}{*}{ Formula fed } & Yes & 02 & 2.8 \\
\hline & No & 70 & 97.2 \\
\hline \multirow{2}{*}{ Bottle fed } & Yes & 04 & 5.6 \\
\hline & No & 68 & 94.4 \\
\hline \multirow{2}{*}{ Malnutrition } & MAM & 53 & 73.6 \\
\hline & SAM & 38 & 52.8 \\
\hline
\end{tabular}


PURI ET AL.: ASSESSMENT OF ANTHROPOMETRIC MEASUREMENT OF UNDER 5 AGES OF CHILDREN IN...

Bivariate analyses reported that occupation of father; birth weight and weight gain during pregnancy were significantly associated factors with malnourished children (Table 2).

Table 2: Association between malnutrition and factors related to malnutrition $(n=72)$

\begin{tabular}{|c|c|c|c|}
\hline Characteristics & $\begin{array}{c}\text { Chi-square for } \\
\text { Trend/T Value }\end{array}$ & Odds Ratio & P Value \\
\hline Occupation of father & 7.39 & $4.44(1.45-13.57)$ & 0.015 \\
\hline Birth weight & 5.7 & - & $<0.0001$ \\
\hline Weight gain during pregnancy & 2.15 & - & 0.034 \\
\hline
\end{tabular}

When birth weight was considered, babies with lower birth weight $(2465 \pm 400 \mathrm{gm})$ were at greater risk of being malnourished and babies with higher birth weight $(3000 \pm 331 \mathrm{gm})$ were at lesser risk and the relationship is statistically highly significant $(\mathrm{t}=5.7$, $\mathrm{P}<0.0001$ ). With occupation of father was taken into account, the odds of having malnourished child when father was less educated were 4.44 , compared to more educated father $(\mathrm{P}=0.015)$. Also, mothers with lower mean weight gain during ANC period $(7.06 \pm 2.2)$ has more chance of having malnourished baby and mothers with higher weight gain during pregnancy $(8.42 \pm 2.8)$ has lesser chances of having a malnourished child and the relationship is statistically significant $(\mathrm{t}=2.15, \mathrm{P}=0.034)$. Multivariate analysis reveals birth weight is the only significantly related factor with MAM $(\mathrm{P}=0.001)$ Comparison of tribal and non-tribal group was mentioned in Table 3.

Table 3: Association between malnutrition and factors related to tribal $(n=72)$

\begin{tabular}{|c|c|c|c|}
\hline Factor & OR & T Value/Chi sq. Value & P Value \\
\hline Age of mother at first Delivery & - & 3.97 & $<0.0001$ \\
\hline Education & $4.8(1.12-20.48)$ & 3.42 & 0.03 \\
\hline Income & $13(1.5-110.5)$ & 6.3 & 0.008 \\
\hline SES & $10.6(2.2-49.5)$ & 9 & 0.002 \\
\hline
\end{tabular}

It was observed that when tribal and non-tribal children were compared, age of mother at first delivery, education, income and socio-economic status were found to be significantly related to tribals. Age at the first delivery among tribals was found to be lesser $(22.2 \pm 1.6)$ when compared to non-tribals $(27.8 \pm 4.2)$ and the relationship was statistically significant $(\mathrm{P}<0.0001)$. It is also revealed that tribals had odds of almost 5 times more for having lower education, when compared to non-tribals $(\mathrm{P}=0.03)$. When income is considered, tribals have odds of 13 for having lower income, when compared to non tribals and the relationship is highly significant (Chi sq.$6.3, \mathrm{P}=0.008)$. The odds of having lower SES among tribals are 10.6, when compared to non-tribals and the relationship is highly significant $(\mathrm{P}=0.002)$.

\section{DISCUSSION}

The current study states that the proportion of underweight, stunting and wasting was $54.17 \%, 36.11 \%$ and $45.8 \%$ respectively. Compared to this, Kerala based study by Philip et al. (2016) in similar settings revealed that the lower proportions of underweight, stunting and wasting was $39 \%, 38 \%$ and $20.5 \%$ respectively. The melghat based study by Talapalliwar et al. (2014), the overall prevalence of underweight, stunting and wasting was $60.9 \%, 66.4 \%$ and $18.8 \%$ respectively, which is way low than compared to present study. According to Deshmukh et al. (2013), the prevalence of stunting was observed as $52.3 \%$ and severe stunting was $25.1 \%$ in his study. When only SAM children were considered, the prevalence of SAM among children was $4.14 \%$ in study by Pravana et al. (2017) and current study had $52.8 \%$ SAM children, which shows a very large difference with high proportion in current study. According to Birdi et al. (2014), children were most affected with 54\% undernutrition in similar group. In the study by Yadav et al. (2016), they found that $41.3 \%$ were underweight and $14 \%$ were severe underweight

In this present study, the mother's age at first delivery was a significant independent determinant for malnourishment. Similar findings were observed by Deshmukh et al. (2013). Talapalliwar et al. (2014) reported that age of mother at her first pregnancy and birth weight of child are significantly related to malnutrition, which matches to findings of present study. 
According to study by Pravana et al. (2017), mother's age at first delivery was significantly associated with SAM. Present study reports odds among less educated father of 4.44 (1.45 - 13.57) for having malnourished child as compare to higher educated father. Also according to Deshmukh et al. (2013), the significant determinants of stunting were found to be fathers' occupation, which is very similar finding in present study. The father's occupation had significant impact on stunting and children whose father were skilled workers and laborers including those working at home had significant higher odds of being stunted (OR - 1.6 to 3.4) or severely stunted (OR - 2.1 to 6.6) than those whose father were engaged in service or business. In the study by Yadav et al. (2016), father's occupation had modest effect on underweight prevalence $(\mathrm{p}=0.135)$.

When income is considered, tribals have odds of 13 for having lower income, when compared to non tribals and the relationship is highly significant (Chi sq.6.3, $\mathrm{P}=0.008$ ), which is similar to study by Deshmukh et al. (2013). In the study by Yadav et al. (2016), it found that statistically highly significant $(\mathrm{p}=0.0001)$ number of children were underweight in lower socioeconomic status (52.5 and 55.4\% respectively in class IV and V). Similar findings were reported worldwide as Socioeconomic status was found to be significantly associated with SAM, a finding consistent with those of case-control studies from India, Pakistan, Iran, Vietnam and Ethiopia (Mishra et al., 2014) (Jamro et al., 2012) (Nandy et al., 2005) (Ruwali, 2011) (Niraula et al., 2013). This could be explained by the fact that children from families of low socioeconomic status have limited access to food, health services, hygiene and sanitation.

After multivariate analysis, present study reported that birth weight is the only significant factor related to malnutrition while study by Pravana et al. (2017) reports that mother's age at birth, birth interval, socioeconomic status, father's educational level and initiation of complementary feeding were statistically significantly associated with SAM. Another study by Ghosh and Varerkar (2019), on multivariate analysis, age was found to be associated with wasting, while current study reported birth weight as the risk of significance.

\section{CONCLUSION}

In this study, mother's age at birth, father's educational level and birth weight were significantly related determinants of SAM among children under 5 years of age. An effective family planning programme, awareness for delay marriage, the provision of education to fathers, proper nutrition to ANC mothers for weight gain, regular ANC visits are needed to address these determinants in an effective and timely manner. There is a need for further studies on community basis and need to be conducted at multiple centers.

\section{ACKNOWLEDGEMENT}

We would like to acknowledge Dr Manoj Talapalliwar for his valuable guidance and support. We would like to express our sincere gratitude and deep appreciation to all the individuals who helped us directly or indirectly to carry out this study successfully, parents of the participants.

\section{REFERENCES}

Arif H.S., 2017. Malnutrition trends in preschool children from a primary healthcare center in Baghdad: A comparative two-year study (2006 and 2012). Qatar Med. J., 2017(2): 5. http://www.qscience.com/doi/10.5339/qmj.2017. 5

Black R.E., Victora C.G., Walker S.P., Bhutta Z.A., Christian P. and de Onis M., 2013. Maternal and Child Undernutrition and Overweight in LowIncome and Middle-Income Countries." Lancet, 382(9890): 427-451. https://www.sciencedirect.com/science/article/pi i/S014067361360937X

Birdi T.J., Joshi S., Kotian S. and Shah S., 2014. Possible Causes of Malnutrition in Melghat, a Tribal Region of Maharashtra, India. Glob J. Health Sci.,

6(5). https://www.ncbi.nlm.nih.gov/pmc/articles/PMC 4825484/

Black R.E., Alderman H., Bhutta Z.A., Gillespie S., Haddad L. and Horton S., 2013. Maternal and child nutrition: building momentum for impact. Lancet, $\quad 382(9890)$ : 372-5. https://www.thelancet.com/journals/lancet/articl e/PIIS0140-6736(13)60988$5 /$ fulltext?rss=yes\&code=lancet-site

Black R.E., Alderman H., Bhutta Z., Gillespie S., Haddad L. and Horton S., 2013. Maternal and Child Nutrition June, 2013 \n. Lancet, 382(9890): 37172. https://www.thelancet.com/journals/lancet/articl e/PIIS0140-67361361100-9/fulltext 
PURI ET AL.: ASSESSMENT OF ANTHROPOMETRIC MEASUREMENT OF UNDER 5 AGES OF CHILDREN IN...

Debnath A. and Bhattacharjee N., 2014. Factors associated with malnutrition among tribal children in India: A Non-parametric approach. Journal of Tropical Pediatrics, 60: 211-5. https://academic.oup.com/tropej/articleabstract/60/3/211/1622041

Deshmukh P.R., Sinha N. and Dongre A.R., 2013. Social determinants of stunting in rural area of Wardha, Central India. Medical Journal Armed Forces India, 69: 213-7. https:/www.sciencedirect.com/science/article/pi i/S0377123712002468

Ghosh S. and Varerkar S.A., 2019. Undernutrition among tribal children in Palghar district, Maharashtra, India. Vellakkal S, editor. PLoS One, 14(2): e0212560.

http://dx.plos.org/10.1371/journal.pone.0212560

Grieken A.v., Renders C.M., Wijtzes A.I., Hirasing R.A. and Raat H., 2013. Overweight, Obesity and Underweight Is Associated with Adverse Psychosocial and Physical Health Outcomes among 7-Year-Old Children: The "Be Active, Eat Right" Study. Bruce A, editor. PLoS One, 8(6):e67383.

https://dx.plos.org/10.1371/journal.pone.006738 3

Jamro B., Junejo A.A., Lal S., Rasool Bouk G., Jamro S., 2012. Risk factors for severe acute malnutrition in children under the age of five year in Sukkur T.T. Pak. J. Med. Res., 51(4): 111-3. http://applications.emro.who.int/imemrf/Pak___ Med_Res/Pak_J_Med_Res_2012_51_4_111_11 3.pdf

Manjunath R., Jagadish Kumar K., Kulkarni P., Begum K. and Gangadhar M.R., 2014. Malnutrition among under-five children of Kadukuruba tribe: Need to reach the unreached. J. Clin. Diagnostic Res., $\quad \mathbf{8}(7)$ : JC01-JC04. https:/www.ncbi.nlm.nih.gov/pmc/articles/PMC 4149088/

Mishra K., Kumar P., Basu S., Rai K. and Aneja S., 2014. Risk factors for severe acute malnutrition in children below $5 \mathrm{y}$ of age in India: A casecontrol study. Indian J. Pediatr., 81(8): 762-5. http://link.springer.com/10.1007/s12098-0131127-3
Nandy S., Irving M., Gordon D., Subramanian S.V. and Smith G.D., 2005. Poverty, child undernutrition and morbidity: new evidence from India. Bull World Health Organ, 83(3): 210-6. https://www.scielosp.org/scielo.php?script=sci_a rttext\&pid=S0042-96862005000300014

Niraula S., Barnwal S., Paudel S., Mishra S., Dahal S. and Das S., 2013. Prevalence and associated risk factors with malnutrition among under-five Nepalese children of Borbote village, Ilam. Heal Renaiss, 11(2): 111-8. https://www.nepjol.info/index.php/HREN/article $/$ view/8217

Park S.E., Kim S., Ouma C., Loha M., Wierzba T.F. and Beck N.S., 2013. Community Management of Acute Malnutrition in the Developing World. Pediatr Gastroenterol Hepatol Nutr., 15(4): 210. https://synapse.koreamed.org/search.php?where $=$ aview\&id=10.5223/pghn.2012.15.4.210\&code $=1121 \mathrm{PGHN} \&$ vmode $=$ FULL

Philip R., Vijayakumar K., Indu P., Shrinivasa B., Sreelal T. and Balaji J., 2016. Prevalence of undernutrition among tribal preschool children in Wayanad district of Kerala. Int. J. Adv. Med. Heal. $\quad$ Res., 33 (1): http://www.ijamhrjournal.org/article.asp?issn=2 349-

4220; year $=2015 ;$ volume $=2 ;$ issue $=1 ;$ spage $=33 ;$ ep age $=38$; aulast $=$ Philip

Pravana N.K., Piryani S., Chaurasiya S.P., Kawan R., Thapa R.K. and Shrestha S., 2017. Determinants of severe acute malnutrition among children under 5 years of age in Nepal: A communitybased case-control study. BMJ Open, 7(8). https://bmjopen.bmj.com/content/7/8/e017084?i nt_source $=$ trendmd\&int_medium $=$ trendmd\&int campaign $=$ trendmd

Ruwali D., 2011. Nutritional Status of Children Under Five Years of Age and Factors Associated in Padampur VDC, Chitwan. Heal Prospect, 10:148. https://www.nepjol.info/index.php/HPROSPEC $\mathrm{T} /$ article/view/5639

Talapalliwar M.R. and Garg B.S., 2014. Nutritional Status and its Correlates Among Tribal Children of Melghat, Central India. Indian J. Pediatr., 81(11): 1151-7. 
PURI ET AL.: ASSESSMENT OF ANTHROPOMETRIC MEASUREMENT OF UNDER 5 AGES OF CHILDREN IN...

http://link.springer.com/10.1007/s12098-0141358-y

Tubid D., 2015. Undernutrition among Tribal Children. https://scholar.google.co.in/scholar?hl=en\&as_s $\mathrm{dt}=0 \% 2 \mathrm{C} 5 \& \mathrm{q}=$ Tubid $+\mathrm{D} .+$ Undernutrition + amon g+Tribal+Children. $+2015+$ Jun. $+\&$ btnG $=$

UNICEF, 2014. The State of the World's Children 2014 Every Child Counts [Internet]. UNICEF, pp.1156. https://eric.ed.gov/?id=ED560009

United Nations Children's Fund (UNICEF), 2009. Tracking progress on child and maternal nutrition: a survival and development priority. https://books.google.co.in/books?hl=en\&lr=\&id $=$-qS8H55N7AUC\&oi=fnd\&pg=PA3\&dq= UNICEF.+Tracking + progress + on + child + and $+m$ aternal+nutrition: $+\mathrm{a}+$ survival+and + development +priority.+UNICEF,+2009\&ots=3d6Wcge_I0\&s ig=A-Km2IqIbfVpL25xMHY5ICol7J4

Wang H., Naghavi M., Allen C., Barber R.M., Carter A. and Casey D.C., 2016. Global, regional, and national life expectancy, all-cause mortality, and cause-specific mortality for 249 causes of death,
1980-2015: a systematic analysis for the Global Burden of Disease Study 2015. Lancet, 388(10053): 1459-544.

WHO and UNICEF, 2007. Community-Based Management of Severe Acute Malnutrition. A Joint Statement by the WHO, WFP, the United Nations System Standing Committee on Nutrition and UNICEF, 2007. https://apps.who.int/iris/bitstream/handle/10665/ 44295/9789280641479_eng.pdf

WHO and UNICEF, 2009. WHO child growth standards and identification in infants [Internet]. WHO Library, pp.1-12. https://apps.who.int/iris/bitstream/handle/10665/ 44129/9789241598163_eng.pdf

Yadav S.S., Mittal A., Kumar R., Singh J., Yadav S.T. and Mishra P., 2016. An epidemiological study of malnutrition among under five children of rural and urban Haryana. J. Clin Diagnostic Res., $\quad \mathbf{1 0}(2)$ : LC07-LC10. https://www.ncbi.nlm.nih.gov/pmc/articles/PMC 4800552/. 